\title{
VIBRATION CHARACTERISTICS OF THE HPOTP \\ (High Pressure Oxygen Turbopump) \\ OF THE SSME \\ (Space Shuttle Main Engine) 1
}

\author{
Dara W. Childs, Professor \\ David S. Moyer; Graduate Research Assistant \\ Mechanical Engineering Department \\ Texas A\&M University \\ College Station, Texas 77843
}

\begin{abstract}
A review is presented of various rotordynamic problems which have been encountered and eliminated in developing the current flight engines, and continuing subsynchronous problems which are being encountered in developing a 109\% power level engine. The basic model for the HPOTP including the structural dynamic model for the rotor and housing and component models for the liquid and gas seals, turbine-clearance excitation forces, and impeller-diffuser forces are discussed. Results from a linear model are used to examine the synchronous response and stability characteristics of the HPOTP, examining bearing load and stability problems associated with the second critical speed. Various seal modifications are examined and shown to have favorable consequences with respect to bearing reactions and stability. Difference between linear and nonlinear model results are discussed and explained in terms of simple models.

The transient nonlinear model is used to demonstrate forced subsynchronous motion similar to that observed in test data for models which are lightly damped but stable. The subsynchronous motion

The work reported herein was supported in part by NASA Contract NAS8-34505 from the George C. Marshall Space Flight Center; Thomas Fox, Technical Monitor.
\end{abstract}


results from bearing clearance nonlinearities. Simulation results indicate that synchronous bearing loads can be reduced but that subsynchronous motion is not eliminated by seal modifications alone.

\section{INTRODUCTION}

The SSME (Space Shuttle Main Engine) has been under development by Rocketdyne Division of Rockwell International since the early 1970's. The George C. Marshall Space Flight Center has administered the program development for NASA. The SSME is designed to operate at the following three conditions:

MPL (Minimum Power Level); $\omega=20,900 \mathrm{cpm}$

RPL (Rated Power Level); $\omega=28,200 \mathrm{cpm}$

FPL (Full Power Level); $\omega=30,380 \mathrm{cpm}$

At RPL the turbines develop approximately $1.71 \quad \mathrm{X} \quad 107$ watts $(22,900 \mathrm{Hp})$. FPL is $109 \%$ of RPL. RPL performance is adequate for the equatorial orbits which have been flown to date; however, polar orbits require FPL performance. This paper concerns various rotordynamics problems related to the HPOTP (High Pressure Oxygen Turbopump) which were eliminated in developing a reliable RPL engine and new problems which are being encountered in developing FPL performance.

As compared to more conventional turbomachinery, liquid-rocket-engine turbopumps present the following distinctive rotordynamics development problems :

(a) The units operate in ball bearings which are lubricated with the cryogenic fluid being pumped. The bearings themselves provide virtually no damping.

(b) Because of the extraordinarily low viscosity of liquid oxygen and liquid hydrogen, neither fluid can be effectively used in a squeeze-film damper. Moreover, the presence of these cryogenic fluids precludes the use 
of other fluids in conventional dampers or elastomeric dampers.

(c) Oxygen-compatible motion transducers are under development; however, they are not currently available. Moreover, a typical turbopump design presents severe difficulty in access to the rotating assembly for relative motion measurements; particularly, when access for motion measurements was not a consideration in the initial design. Vibration data for the SSME turbopumps has largely been confined to the output of accelerometers mounted on the housing. For most of the development period of the HPOTP, there has been no speed probe plckup and no once-per-revolution phase mark from the shaft to use in data analysis.

The calculated linear critical speeds for the current nominal HPOTP are at approximately $12,500 \mathrm{cprn}$ $(208 \mathrm{~Hz})$ and $32,500 \mathrm{cpm}(540 \mathrm{~Hz})$. These calculated values are for complete housing-rotor models including seals, clearance-excitation forces, gyroscopic coupling, etc. The arrangement of the high pressure turbopumps in the powerhead are illustrated in figure 1. The HPOTP rotating assembly is illustrated in figure 2. The undamped, zero-running-speed, rotor-housing modes associated with the first and second critical speeds are illustrated in figure 3. The modeshape associated with the first critical speed primarily involves overhung motion of the turbine with relatively small amplitudes at the bearings and main impeller. The modeshape associated with the second critical speed involves large amplitudes at the main impeller and bearings with small amplitudes at the turbine.

Initial vibration problems with the HPOTP involved motion associated with the first critical speed. Synchronous and subsynchronous (at approximately $200 \mathrm{~Hz}$ ) motion was excessive. This problem was remedied by changing the turbine 
interstage seal from a stepped-labyrinth configuraton to a convergent taper seal with a honeycomb stator and a smooth rotor. This change was implemented based on the beneficial consequences of a similar change in the pump interstage seals of the HPFTP (High Pressure Fuel Turbopump) [1].

The second problem associated with the HPTOP involved subsynchronous vibrations at approximately $400-420 \mathrm{~Hz}$. This motion tended to initiate when the running speed reached approximately $400 \mathrm{~Hz}$, and persisted as subsynchronous motion when the running speed was increased. A failure and explosion of the HPOTP occurred in a test run when the running speed first traversed the maximum-amplitude frequency range and then was reduced to and remained at the now synchronous frequency. The failure was attributed to an inadequate bearing-carrler design which caused unequal load sharing of the bearings. Subsequently, redesigned bearing carriers eliminated the "400 $\mathrm{Hz}^{\prime \prime}$ subsynchronous motion. The general feeling was that the new bearing carrier designs caused a more equal load sharing and maintained the correct axial bearing preloads, thus realizing the "expected" radial stiffness of the bearings and elevated the rotor second critical speed.

The bearing-carrier redesign was sufficient to yield a reliable pump for RPL operations: however. demonstration of FPL capability has been impeded by repeated occurrence of subsynchronous motion in the 450-500 Hz frequency range. The incidence of this motion rarely occurs during initial operation at higher power levels, but tends to develop after an accumulation of time and develops more rapldiy with higher synchronous vibration levels. However, once a unit begins to "whirl", it will repeatedly whirl, generally with progressively increasing severity. The frequency of the subsynchronous motion is sometimes at a fixed fraction of running speed ranging from 88 to $95 \%$. This "tracking" characteristic is in marked contrast to the earlier "400 $\mathrm{Hz}^{\prime \prime}$ phenomenon where the whirl-frequency of the 
subsynchronous motion remained constant, relatively independent of running speed.

Post-run inspection of turbopumps has revealed that, although the balls in some bearings, primarily bearing 2, appear to be unblemished, their diameters have in fact, been reduced by as much as $0.17 \mathrm{~mm}$ in some cases. The cause of this dimensional attrition is unknown, but has been ascribed to either excessive radial loads or the absence of radial loads which leads to skidding.

The analysis results which have been completed to date and are reported herein do not provide a complete or comprehensive explanation for the measured dynamic characteristics of the HPOTP; however, they do provide answers for the following questions:

(a) What are the linear dynamic characteristics of the nominal turbopump model ith respect to critical-speed locations, bearing reactions, predicted housing accelerometer levels, and predicted onset speeds of instability?

(b) How can the linear dynamic characteristics be improved by feasible, physical modification of the HPOTP seals?

(c) What causes the subsynchronous motion?

(d) From a rotodynamics viewpoint, what are the principal problems experienced by the HPOTP?

(e) What improvements are possible with the HPOTP?

The following section briefly describes the structure and components of the rotordynamic model, with the succeeding section describing the results of linear and nonlinear analysis.

THE ROTORDYNAMICS MODEL

Structural Dynamics Model. The structuraldynamics model of the rotor and the housing form the 
basic framework of the turbopump model. Both the housing and rotor structural dynamics models used here were developed by Rocketdyne. A general three-dimensional finite-element approach was used to model the HPOTP housing without the rotor. A lumped parameter model was developed for the rotor using beam structural elements and lumped masses and inertias. The rotordynamics model uses modes from the housing model (without the rotor) and free-free rotor modes.

Bearings. The bearings are the structural elements which tie the rotors and housing together. As illustrated in figure 2, there are two sets of bearings. The net load from each set is transmitted through a plate-cylinder structure to the housing. The bearings in a bearing set are axially preloaded against each other, but are not designed to accept axial thrust loads from the turbopumps. A balance-piston arrangement at the discharge of the main impeller absorbs axial thrust, and radial clearances are provided at the bearing outer faces to allow the bearings to slip axially without developing excessive axial loads.

Experience and limited test data [2] for the SSME bearings indicate a nominal stiffness of approximately $8.76 \times 107 \mathrm{~N} / \mathrm{m}$. This is approximately one half of the values predicted by A. B. Jones-based analysis [3].

The radial clearances provided at the bearings to permit axial motion provides an essential "dead-band" nonlinearity. The clearance values used in this study are

$$
\delta_{P}=0.0127 \mathrm{~mm}, \delta_{T}=0.0127 \mathrm{~mm}
$$

where $\mathrm{P}$ and $\mathrm{I}$ denote pump and turbine bearings.

Liquid Seals. Liquid wear-ring seals are provided at the inlet and discharge of the boost impeller. The current inlet seal is a stepped labyrinth design with four cavities. The current 
discharge seal is a three segment, stepped seal. Each constant-radius seal segment has a series of circumferential grooves.

Experience and limited test data [3] have shown that labyrinth or serrated seals of the type currently employed on the impeller inlet and discharge yield stiffness and damping coefficients which are substantially smaller than corresponding values for smooth constant clearance seals. Replacing the current grooved boost-impeller wear-ring seals with plain annular seals has the potential for a beneficial increase in stiffness and damping in the HPOTP. In fact, as the following discussion explains, various additional possibilities exist for optimizing seals.

The force-motion model for liquid seals has the form

$$
-\left\{\begin{array}{c}
F_{X} \\
F_{Y}
\end{array}\right\}=\left[\begin{array}{cc}
K & k \\
-k & K
\end{array}\right]\left\{\begin{array}{l}
X \\
Y
\end{array}\right\}+\left[\begin{array}{cc}
c & c \\
-c & c
\end{array}\right]\left\{\begin{array}{l}
\dot{X} \\
\dot{Y}
\end{array}\right\}+\left[\begin{array}{cc}
M & m \\
-m & M
\end{array}\right]\left\{\begin{array}{l}
\ddot{X} \\
\ddot{Y}
\end{array}\right\}
$$

In this model ( $X, Y$ ) are the components of the relative motion between the rotor and housing. Black, et al. [5, 6] were responsible for most of the analytical developments related to the analysis of seals leading to the definition of stiffness, damping, and added-mass coefficients. His analysis demonstrates that the "cross-coupled" stiffness coefficient, $k$, arises solely due to fluid rotation within the seal. As a fluid element proceeds axially along an annular seal, shear forces at the rotor accelerate or decelerate the fluid tangentially until an asymptotic value is reached. For a seal with the same directionally-homogeneous surface-roughness treatment on the rotor and the housing, the average asymtotic tangential velocity is $R \omega / 2$ where $R$ is the seal radius and $\omega$ is the rotor running speed.

The cross-coupled stiffness coefficient $k$ acts in opposition to the direct damping coefficient $C$ to destabilize rotors. Hence, steps which can be taken 
to reduce the net fluid rotation within a seal will improve stability by reducing $k$. The following two steps are currently under consideration for providing more net damping to the HPOTP rotating assembly:

(a) If the inlet tangential velocity can be reduced, the high axial velocities in a cryogenic seal are such that the fluid may proceed through a seal without substantially increasing its tangential velocity. An antivortex web has been proposed at the inlet to the boost-impeller inlet seal to reduce the inlet tangential velocity and yield a reduced $k$. This practice has been followed previously for the labyrinth seals of high pressure compressors.

(b) Von Pragenau [7] has recently demonstrated that the asymptotic tangential velocity can be modified if a different surface roughness is used for the rotor and stator elements. Rough rotor/smooth stator and smooth rotor/rough stator combinations yield higher and lower asymptotic values, respectively. Von Pragenau calls the rough stator/smooth rotor configuration a "damper seal" because of its enhanced stability characteristics. The roughness has the additional potential benefit of reducing leakage. Damper seal configurations are presently under consideration for both the inlet and discharge seals of the boost impeller.

Liquid seal coefficients for the boost impeller seals were calculated based on analysis by Childs and Kim [8]. Current analyses yield finite-length solutions for constant-clearance or convergent-tapered seals with different but directionally-homogeneous surface roughness treatments on the rotor and stator.

Gas Seals. The HPOTP turbines are shrouded, and single-cavity tip seals are provided to reduce 
leakage between the turbine shroud and the stator. The interstage seal between the turbines uses a honeycomb stator element with a smooth rotor and inlet anti-vortex $r i b s$ to reduce the inlet tangential velocity component. A floating-ring shaft seal is provided at the turbine discharge to restrict leakage of the hot turbine gases towards the lox within the pump. The flow across this seal is choked.

Seal coefficients calculations used in the study are based on the analyses of Nelson [9]. The analyses apply to constant-clearance or convergent taper geometries, account for the development of tangential velocity within the seals, and different but directionally-homogeneous surface roughness on the rotor and stator.

Turbine Clearance Excitation Forces. Clearance excitation forces are developed by turbines due to the dependency of local efficiency on local clearances. The destabilizing force is modeled by

$$
\left\{\begin{array}{l}
F_{X} \\
F_{Y}
\end{array}\right\}=\left[\begin{array}{cc}
0 & k_{T} \\
-k_{T} & 0
\end{array}\right]\left\{\begin{array}{l}
X \\
Y
\end{array}\right\} ; k_{T}=\frac{\beta T}{D_{p} H}
$$

where $T$ is the turbine torque, $D p$ is the average pitch diameter of the turbine blades, $H$ is the average height, and $\beta$ defines the change in turbine efficiency due to uniform changes in clearance. Again, the components ( $X, Y$ ) of Eq. (3) define the displacement of the turbine relative to the housing. Thomas initially identified this destablizing phenomenon [10], while Alford [11] subsequently and independently developed the same model. Test results for shrouded turbines have yielded values for $\beta$ on the order of $0.6[12]$.

Impeller-Diffuser Forces. A test program has been under way at the California Institute of Technology for some time to measure the static and dynamic forces experienced by a pump impeller in either a volute or a vaned diffuser. Chamieh et al. 
[13] have defined the following model on the basis of static measurements of an jmpeller within a vaned diffuser:

$$
-\frac{1}{\rho A_{2} V_{2}^{2}}\left\{\begin{array}{l}
F_{X} \\
F_{Y}
\end{array}\right\}=\left[\begin{array}{cc}
K^{*} & k^{*} \\
-k^{*} & K^{*}
\end{array}\right]\left\{\begin{array}{l}
X / R_{2} \\
Y / R_{2}
\end{array}\right\}=\left[\begin{array}{cc}
-2.0 & 0.7 \\
-0.7 & -2.0
\end{array}\right]\left\{\begin{array}{l}
X / R_{2} \\
Y / R_{2}
\end{array}\right\}
$$

where $R_{2}$ is the impeller radius, $p$ is the fluid density, $v_{2}=R_{2} \omega$ is the impeller tip velocity, and $A_{2}=2 \pi R_{2} b_{2}$ is the exit flow area. Note that the direct-stiffness coefficient in Eq. (4) is negative, i.e., the impeller-diffuser force causes a reduction in rotor stiffness. From Eq. (4), the dimensional impeller-diffuser coefficients are defined by

$$
\begin{aligned}
& \bar{k}=k^{*} \frac{\rho A_{2} V_{2}^{2}}{2 R_{2}}=K^{*}\left(\pi \rho b_{2} R_{2}{ }^{2}\right) \omega^{2} \\
& \bar{k}=k^{*}\left(\pi \rho b_{2} R_{2}{ }^{2}\right) \omega^{2}
\end{aligned}
$$

\section{ANALYSIS PROCEDURES AND RESULTS}

Introduction

The radial clearances which are provided at the outer races of the bearings to permit axial slipping and prevent the bearings from absorbing axial loads provide the essential nonlinearity in a rotordynamics model for the HPOTP. If these "dead band" clearances are eliminated, the resultant model is basically linear. As the following sections demonstrates, the results of linear and nonlinear analysis differ substantially, but linear analysis remains an efficient procedure for general characterization of the turbopump's rotordynamics.

Linear Analysis Procedure and Results Rotordynamic Characteristics of the Nominal Model

The analysis procedure used here is basically the same as that outlined in reference [1]. Modal 
coordinates based on the zero-running-speed coupled rotor-housing mode are used. Gyroscopic coupling and forces due to seals, turbine clearance-excitation, the interaction of impellers and diffusers, damping, etc. couple the modal coordinates via modal stiffness, damping, and inertial matrices. The onset speed of instability for a turbopump configuration is defined by calculating the complex eigenvalues of the system dynamic matrix at various speeds. Synchronous-response amplitudes of bearing reactions and acceleration levels of accelerometers mounted on the turbopump housing due to imbalance are calculated.

For the purposes of the present discussion, the nominal linear model is defined as having bearing stiffness on the order of $8.76 \times 10^{7} \mathrm{~N} / \mathrm{m}\left(.5 \times 10^{6}\right.$ los/in). Calculated seal coefficients are based on the dimensions of seals currently used in the turbopump. The clearance-excitation force coefficient at the turbines use a $B$ of 0.4 .

An inspection of the modeshapes of ligure 3 indicates that the clearance-excitation force at the turbine represents the dominant destabilizing excitation force for motion associated with the first. critical speed. Following the initial $1400 \mathrm{~Hz}^{\prime \prime}$ subsynchronous vibration problem, the suggestion was made [15] that impelier-diffuser-interaction forces provided the principal destablizing mechanism for motion associated with the second critical speed. The published cross-coupling coefficients of $\mathrm{Eq}$. (4) certainly supported this view. If the nominal model includes the stiffness coefficients of Eq. (4), the OSI (Onset Speed of Instability) is only $17.200 \mathrm{cpm}$. However, the stability is very sensitive to damping; and the additional $875 \mathrm{Ns} / \mathrm{m}(5.0 \mathrm{lb}$ sec/in) at the main impeller with no bearing damping elevates the OSI to $30,480 \mathrm{cpm}$. The whirl frequency at OSI is 536 Hz. This concentrated damping coefficient acts to restrain relative motion between the rotor and housing, and is used in the nominal linear model.

Figure 4 illustrates the bearing reaction for running speeds from 5,000 to $40,000 \mathrm{cpm}$. The first 
and second critical speeds are evident, with the second critical speed clearly having little or no damping. Figure $5(\mathrm{a})$ illustrates the same results for speeds from $5,000 \mathrm{cpm}$ to FPL. Figures $5(\mathrm{~b})$ and (c) illustrate predicted acceleration levels for accelerometers mounted on the housing at the pump and turbine ends of the turbopump. Clearly, FPL is quite near the predicted second critical speed. Also, while the bearing reactions are responsive to the "rotor" oritical speeds, the housing accelerometer levels may respond more sharply to rotor-housing combined modes. This is particularly true for the first critical speed at approximately $12,500 \mathrm{rpm}$ However, the predicted accelerometer levels are quite responsive to motion associated with the "rotor" second critical speed at approximately $32,500 \mathrm{cpm}$.

(a) Response. The proximity of the second critical speed to FPL is a continuing cause for concern with respect to excessive bearing loads. Even modest losses of bearing stiffnesses are sufficient to drop the second critical speed into the operating range.

(b) Stability. Based on the prior $1400 \mathrm{~Hz}^{\text {" }}$ experience with this turbopump, the second critical speed appears to be IIghtly damped and subject to instability.

\section{Seal Modifications to Improve Rotordynamic Response and Stability}

The preceding material demonstrated the relevant dynamic characteristics of the HPOTP with respect to response and stability. The present section deals with predicted improvements in rotordynamic response due to the following seal modifications:

(a) Replace the current inlet and discharge seals of the boost impeller with "damper" seals using a rough stator and smooth rotor. Test results at Texas A\&M University of proposed damper seal and smooth seals fight candidates show a substantial reduction in 
leakage due to roughness and slight increases in direct stiffnesses and net damping [8].

(b) Replace the current unshrouded impeller with shrouded impellers and use the outer surfaces of the shrouded impeller to develop seal forces.

Figure 6 illustrates the bearing reactions which result for choice (a), and a comparison of this result with the nominal-model results of figure 5 (a) indicates a sharp reduction in bearing reactions. Moreover, the OSI is increased moderately. Table 1 provides a summary of the results for both the nominal configuration and the seal modifications cited above and demonstrates that the damper seals yield a predicted reduction in bearing loads on the order of $37 \%$ and an increase of the predicted OSI to $36,350 \mathrm{rpm}$.

\begin{tabular}{|l|c|c|c|c|c|c|}
\hline & OSI & WHIRL & \multicolumn{4}{|c|}{ BEARING REACTIONS } \\
CONFIGURATION & (cpm) & FREQ. & \multicolumn{3}{|c|}{ at FPL (1 bs) } \\
(Hz) & $\mathbf{1}$ & $\mathbf{2}$ & $\mathbf{3}$ & $\mathbf{4}$ \\
\hline Nominal & 30,480 & 536 & 553 & 635 & 667 & 548 \\
\hline $\begin{array}{l}\text { Nominal with } \\
\text { With Boost- } \\
\text { Impeller Seals }\end{array}$ & 36,350 & 576 & 251 & 349 & 513 & 411 \\
$\begin{array}{l}\text { Nominal with } \\
\text { Shrouded- } \\
\text { Inducer Seal }\end{array}$ & 59,950 & 315 & 80 & 85 & 57 & 58 \\
\hline
\end{tabular}

Table 1. Linear OSI, whirl frequency, and predicted bearing reactions at FPL.

Figure 7 illustrates the results for the shrouded inducer configuration. Stated briefly, the second critical speed is simply eliminated for this configuration, and OSI is much greater than FPL.

An assessment of the results presented in figures 6,7 , and table 1 supports the following general conclusions : 
(a) Modification of the boost impeller seals has the potential for significantly reducing bearing reactions at FPL as compared to the nominal model. However, the second critical speed remains only slightly above FPL and any loss of bearing stiffness will drop it into the operating range.

(b) The damper-seal modification yields a predicted increase of the OSI by $19 \%$.

(c) The shrouded-inducer design eliminates both the second critical speed and the stability problem.

Nonlinear Analysis Procedures and Results

As noted previously, the bearing "dead-band" clearances provide the essential nonlinearity in the HPOTP model. The bearing clearances interact with the effects of side loads and rotor imbalance to yield significantly different results for a nonlinear model than those predicted by linear models.

Figure 8 illustrates the analytical model used by Yamamoto [14] to investigate the influence of bearing clearances on rotordynamic response in the absence of side loads. For zero bearing clearances, the model of figure 8 reduces to a simple Jeffoott model with viscous external damping. Figure 9 illustrates the response characteristics for a progressive increase in the ratio of bearing clearance to imbalance eccentricity $\hat{e}=e / a$. The results are for a damping ratio of $2.5 \%$, and indicate the speed location of maximum bearing reactions is reduced by increasing $\hat{e}$. Moreover, the drop in amplitude for speeds above the maximum bearing-load can be preciptious. The response characteristics of figure 9 can give rise to "jump" phenomena with the synchronous vibration level jumping either up or down for very small changes in running speed. Flight data for the HPOTP have demonstrated sudden step increases in accelerometer levels.

From these results, one would anticipate that bearing clearances could easily drop the peak-bearing-load running speed location associated 
with the second critical speed into the operating range. In fact, parametric studies of the bearing clearances clearly confirm this result [15]. They also confirm that peak-bearing-load speeds can be reduced below FPL for sufficiently large clearances. Hence for a given running speed, a nonlinear model with bearing clearances can yield either substantially larger or smaller bearing reactions than the linear model.

The nonlinear model was verified by comparison to results from the linear model, e.g., the secondcritical-speed location at $32,500 \mathrm{cpm}$ was obtained for zero bearing clearances. Figure 10 illustrates the bearing 2 reaction magnitude and turbine acceleration signals at FPL for the nominal model with the bearing clearances of Eq. (1). Observe the "clipping" of the bearing reaction magnitudes in figure 10 (a), which results from motion through the bearing deadband. Motion in and out of the deadband results as a combination of static displacement due to the impeller and turbine side loads and elliptical orbits due to imbalance. Bearing clipping generates a nearly periodic impulsive loading at the bearing that excites the beating motion which is evident in the accelerometer signal prediction of figure 10 (b). Spectrum analysis results of the accelerometer signals at FPL and two higher speeds are provided in figure 11 and reveal a subsynchronous signal at $26,500 \mathrm{cpm}(443 \mathrm{~Hz})$. Both the synchronous and subsynchronous signals are observed to decrease as the running speed increases. Observe that the frequency of the subsynchronous motion is consistent with frequencies observed in test data as opposed to the linear predictions of $520 \mathrm{~Hz}$. The linear model corresponding to the result of figure 10 is lightly damped but stable. The nonlinear model remains in a limit cycle motion with subsynchronous components until the destabilizing force components at the main impeller are increased to $250 \%$ of their nominal values, but then diverge exponentially. Based on these observations, the subsynchronous component of figure 11 is deemed to be the result of bearing 
nonlinearities and not the result of an instability. However, the nonlinear subharmonic motion can only be developed for light rotor damping.

The subsynchronous motion of figures 10 and 11 arises at speeds above the maximum synchronous response speed predicted by Yamamoto's model in figure 9. This statement is supported by the results in figure 12 which shows the bearing 2 reaction magnitude predictions at $29,450 \mathrm{cpm}$.

A second nonlinear model configuration which yielded a substantial subsynchronous vibration component was obtained by doubling both the imbalance magnitudes and the destabilizing force coefficients at the main impeller, adding damping at the bearing (350 $\mathrm{Ns} / \mathrm{m}$ or $21 \mathrm{~b} / \mathrm{s} / \mathrm{n}$ ), and increasing the damping at the main impeller to $2625 \mathrm{Ns} / \mathrm{m}(15 \mathrm{lb} \mathrm{s} / \mathrm{in})$. This configuration is predicted to be linearly stable at FPL. Spectral analysis results for this configuration at FPL and two higher speeds are presented figure 12. In this case, the subsynchronous component increases with running speed, while the synchronous component decreases.

The response characteristics of a nonlinear model including bearing clearances is sensitive to many parameters including bearing clearances, imbalance magnitudes, side load magnitudes, damping coefficients, destabilizing force magnitudes, etc., and a study including a systematic variation of all these parameter would be helpful. However, the simulation results of figures 10 through 12 are sufficient to support the following conclusions:

(a) The subsynchronous motion which is evident in these results can be obtained due to bearing-clearance nonlinearies for a linearly-stable but lightly damped model.

(b) A whirl frequency of subsynchronous motion at $440 \mathrm{~Hz}$ is predicted by the nonlinear model as compared to $520 \mathrm{~Hz}$ for the linear model. This whirl frequency reduction results solely from the bearing clearances, and does not require any stiffness reduction in the model at the bearings or elsewhere. 
(c) As predicted by Yamamoto [16] and earlier simulations [15], bearing clearances can drop the peak-vibration running speed into the operating range, and these synchronous vibration loads would appear to pose a more serious threat to bearing lifetime than the subsynchronous motion.

The following options are being pursued to improve the dynamic characteristics of the HPOTP:

(a) Units are being prepared for tests which include a stiffened rotor, damper seals at the boost impeller, and a modified turbine interstage seal.

(b) Although attractive from a dynamics viewpoint, the shrouded inducer design poses serious manufacturing problems and also raises concerns with respect to cavitation performance. Pending resolution of these problems, no test of this configuration are presently scheduled.

Figure 13 illustrates simulation results for the nominal nonlinear model with damper seals at 29,500 cpm. Observe the sharp reduction in synchronous bearing loads. This reduction is due to (a) load sharing by the seals and (b) increases in damping which, according to Yamamoto's predictions, lower the peak bearing reaction amplitudes. Figure 14 illustrates the bearing reaction above FPL. Observe that clipping of the bearing loads due to motion in and out of the deadband has actually increased. The corresponding accelerometer spectrum is given in figure 15, and demonstrates a rich spectrum of subsynchronous components. The damper seals increase bearing-reaction clipping by opposing the side load and moving the rotor towards the center of the bearing clearances. The model is setup with the seal and bearing centers coincident radially. In an actual engine, some lack of concentricity can be expected which might counteract the seals centering action. 
An inspection of figures 13 trough 15 support the following conclusions with respect to implementation of the damper seals:

(a) In accordance with the linear predictions of figure 6 , a marked reduction in synchronous bearing loads is predicted.

(b) Motion in and out of the bearing clearances is increased with a consequent increase in bearing-reaction-magnitude clipping and an increase in subsynchronous motion.

If current bearing distress is the result of excessive synchronous loads, seal modification should be very beneficial. However, if the bearing problems are associated with unloading and ball skidding, seal modifications will be counter-productive.

\section{CONCLUSIONS}

Linear and nonlinear analyses of the HPOTP support the following conclusions:

(a) By linear predictions, the second critical speed is only slightly above the FPL running speed and is lightly damped. Even a modest loss of bearing stiffness is sufficient to drop the second critical speed into the operating range and yield a prediction of excessive bearing loads.

(b) Based on prior test experience, the HPTOP appears to be lightly damped.

(c) The subsynchronous motion which is evident in test results can be obtained in a nonlinear model due to bearing clearances. Motion in and out of the deadband clearances excites subharmonic motion for a stable but lightly damped model.

(d) A whirl frequency of subsynchronous motion at $440 \mathrm{~Hz}$ is predicted by the nonlinear model which is consistent with test results but at odds with a linear prediction of $520 \mathrm{~Hz}$. 
This whirl frequency reduction results solely from the bearing clearances, and does not require any stiffness reduction in the model at the bearings or elsewhere.

(e) Bearing clearances can drop the peak-vibration running speed into the operating range yielding a prediction of excessive bearing loads.

(f) Incorporation of damper seals into the boost impeller seals markedly reduces predicted synchronous bearing loads, but increases bearing-reaction clipping an subsynchronous motion at FPL.

\section{ACKMOWLEDGMENT}

Discussions with Robert Beatty concerning a parallel investigation at Rocketdyne were very helpful to the authors. 


\section{REFERENCES}

1. Childs, D. W., "The Space Shuttle Main Engine High-Pressure Fuel Turbopump Rotordynamic Instability Problem," ASME Trans. J. of Engineering for Power, Vol. 100, January, 1978; pp. 48-57.

2. Beatty, R.F. and Rowan, B. F., "Determination of Ball Bearing Dynamic Stiffness," Proceedings, Second Workshop on Rotordynamic Instability Problems in High Performance Turbomachinery, NASA CP 2250.

3. Jones, A. B.. "A General Theory for Elastically Constrained Ball and Radial Roller Bearings Under Arbitrary Load and Speed Conditions," ASME J. of Basic Engineering, Vol. 82, No. 2, June 1960, pp. 309-320.

4. Black, H. F., and Cochrane, E. A., "Leakage and Hybrid Bearing properties of Serrated Seals in Centrifugal Pumps," Paper G5, 6th International Conference in Fluid Sealing, Munich, German Federal Republic, 27 February - 2 March 1973.

5. Black, H. F., and Jensen, D. N., "Effects of HighPressure Ring Seals on Pump Rotor Vibrations," ASME Paper No. 71-WA/FE-38, Winter Annual Meeting, Washington, D. C., 1971:

6. Black, H. F., Allaire, P. E., and Barrett, L. E., "The Effect of Inlet Flow Swirl on the Dynamic Coefficients of High-Pressure Annular Clearance Seals," Ninth International Conference on Fluid Sealing, BHRA Fluid Sealing Conference, Leeuwenhorst, The Netherlands, April 1981.

7. von Pragenau, G. L., "Damping Seals for Turbomachinery," NASA TP-1987, March 1983.

8. Childs, D. W. and Kim C-H., "Analysis and Testing for Rotordynamic Coefficients of Turbulent Annular Seals with Different, Directionally-Homogeneous Surface-Roughness Treatment for Rotor and Stator Elements, "presented at the Third Rotordynamics Instability Workshop at Texas Texas A\&M University, College Station, TX, May 28-30, 84. 
9. Nelson, C. D., "The Rotordynamic Coefficients of High-Pressure Annular Gas seals," accepted for presentation at the 1984 ASME Gas Turbine Conference.

10. Thomas, J. J., "Instabilie Eigenschwingungen von Turbine Laufern, angefacht durch die Spaltstromungen Stopfbushsen un Beschaufelungen, AEG-Soderdruch, 1958.

11. Alford, J., "Protecting Turbomachinery From Self-Excited Rotor Whirl," ASME Trans. J. of Engineering for Power, October 1965, pp. 333-345.

12. Hauck, L., "Measurement and Evaluation of Swirl-Type Flow in Labyrinth Seals," NASA CP 2250 Rotordynamic Instability Problems in High-Performance Turbomachinery, Proceedings of a workshop held at Texas A\&M University, 10-12 May 1982.

13. Chamieh, D. S., Acosta, A. J., Brennen, C. E., Caughey, T. K., and Franz, R., "Experimental Measurement of Hydrodynamic Stiffness Matrices for a Centrifugal Pump Impeller," NASA CP 2250 Rotordynamic Instability Problems in High Performance Turbomachinery, Proceedings of a workshop held at Texas A\&M University, 10-12 May 1982.

14. Yamamoto, T., "On the Critical Speeds of a Shaft," Memoirs of the Faculty of Engineering, Nagoga University, Vol. 6, No. 2, 1954.

15. Childs, D. W., Rotordynamics Analysis for the HPOTP (High Pressure Oxygen Turbopump) of the SSME (Space Shuttle Main Engine), an Interim Progress Report for NASA Contract NAS8-31233, Dept. of Mechanical

Engineering, The University of Louisville, 1979. 


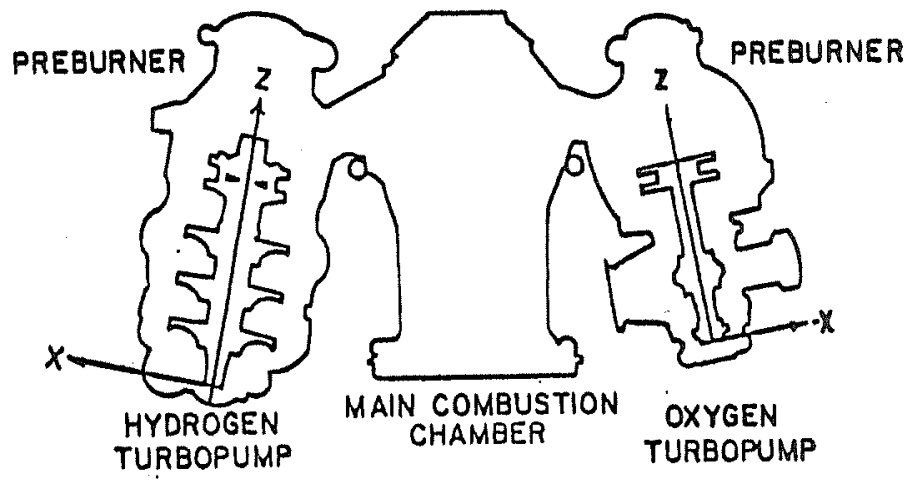

FIgure 1. SSME powerhead component arrangement and local coordinate systems.

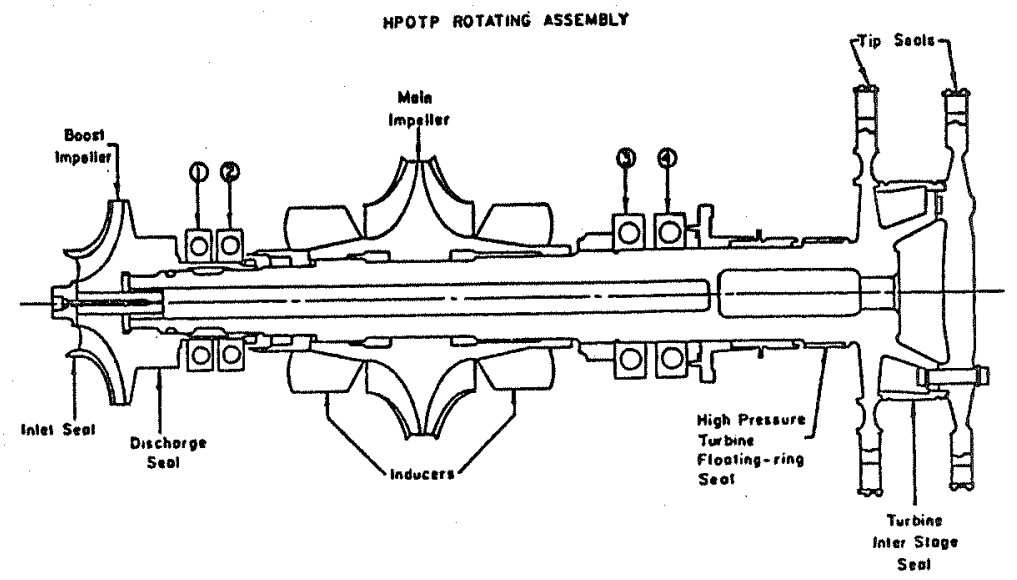

F1gure 2. HPOTP rotating assemblỳ. 

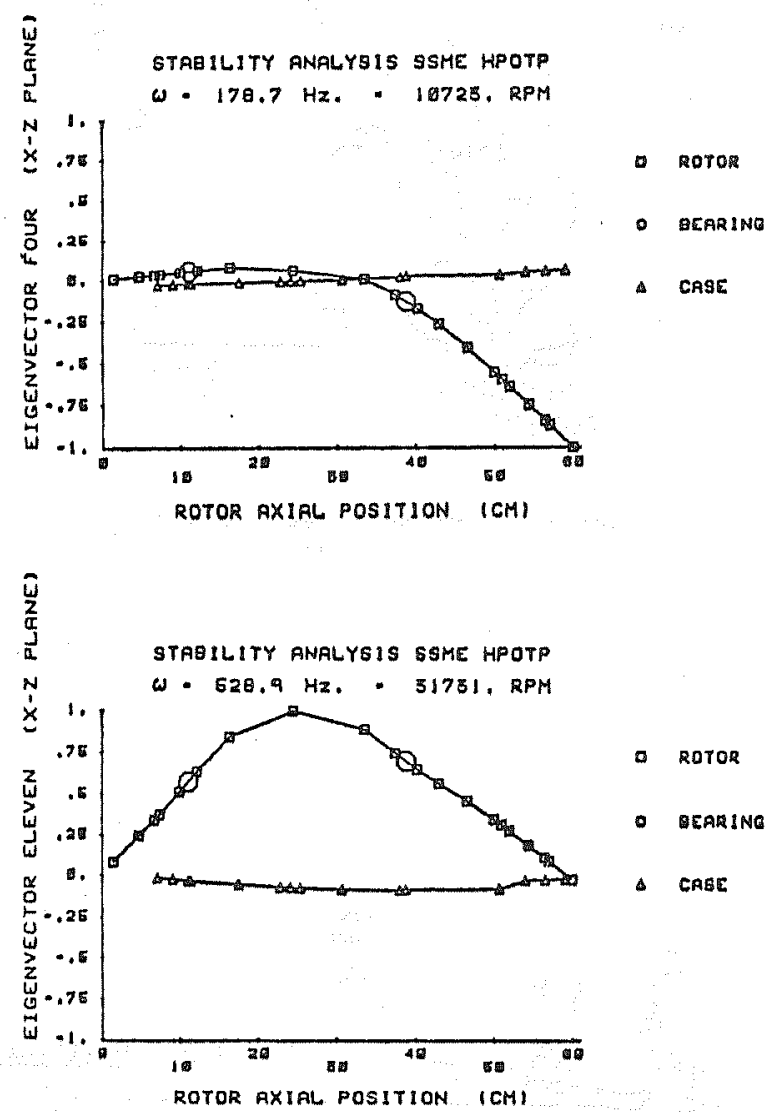

E1gure 3. Undamped, zero-running-speed rotor-housing modes assoclated with the first and second critical speeds. 


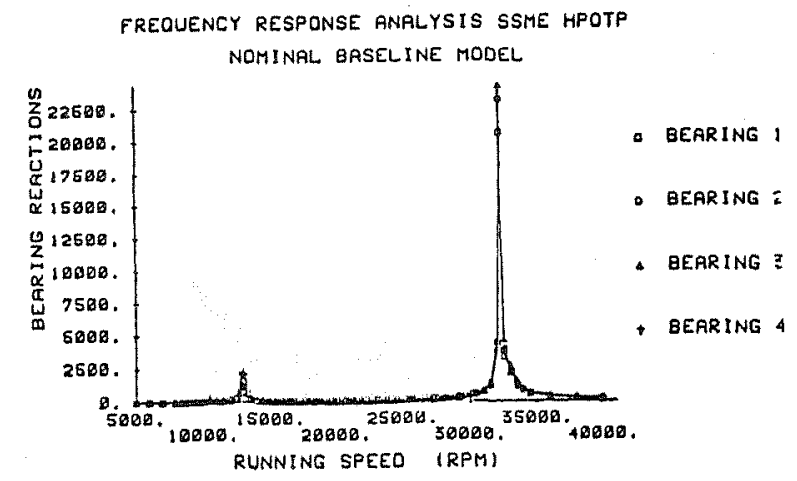

Figure 4. Bearing reactions for the nominal linear model with speeds out of $40,000 \mathrm{cpm}$.

FREOUENCY RESPONSE ANALYSIS SSME HPOTP NOMINAL BASELINE MODEL

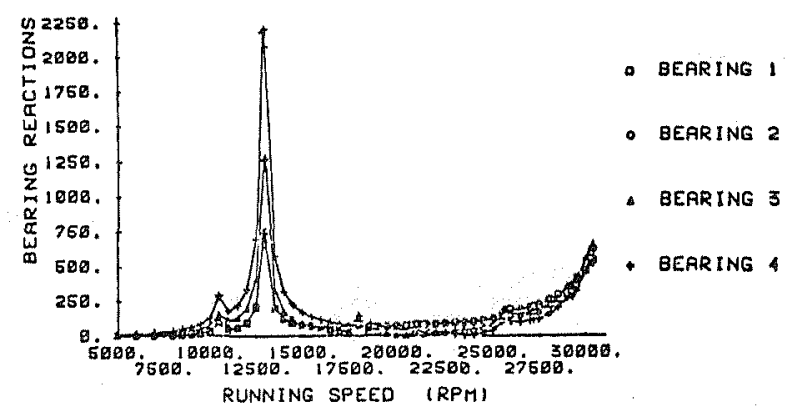

Figure 5 (a). Bearing reactions for the nominal linear model for speeds from 5,000 cpm to FPL.

FREQUENCY RESPONSE ANALYSIS SSME HPOTP NOMINAL BASELINE MODEL

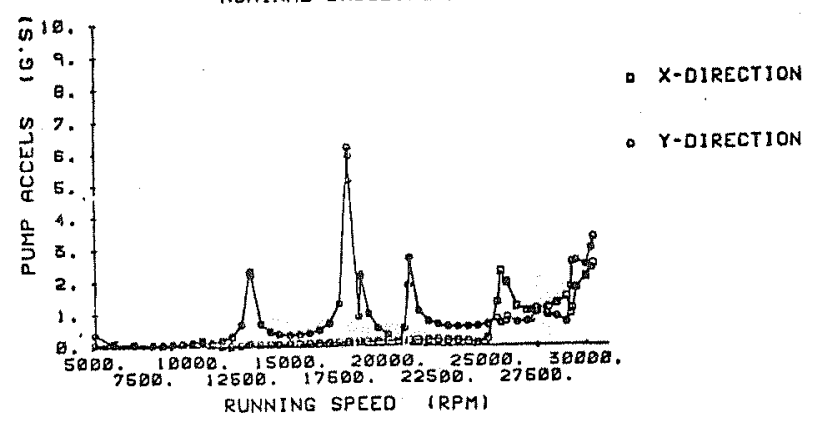

Figure 5 (b). Pump accelerometer levels in the $\mathrm{X}-\mathrm{Z}$ and $\mathrm{Y}-\mathrm{Z}$ planes. 


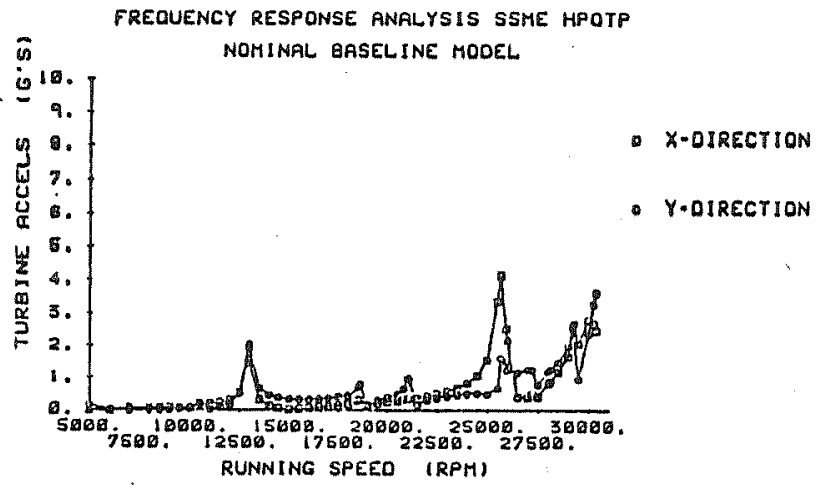

Bigure 5 (c). Turbine accelerometer levels in the $\mathrm{X}-\mathrm{Z}$ and $\mathrm{Y}-\mathrm{Z}$ planes.

FREOUENCY RESPONSE HWFLYSIS SSME HPOTP SMOOTH ROTOR - ROUGH HOUSING FUR : RWR

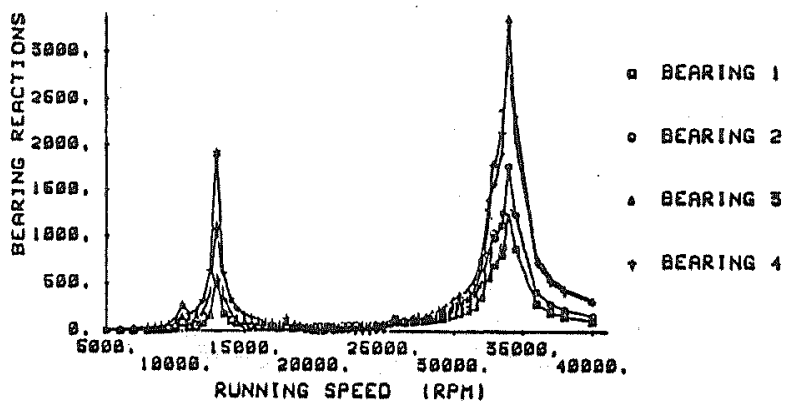

Pigure 6. Bearing reactions for the nominal model with "damper" seal coefflclents for the boost-Impeller inlet and discharge seals. FREOUENCY RESPONSE ANALYAIS SEME HPOTP

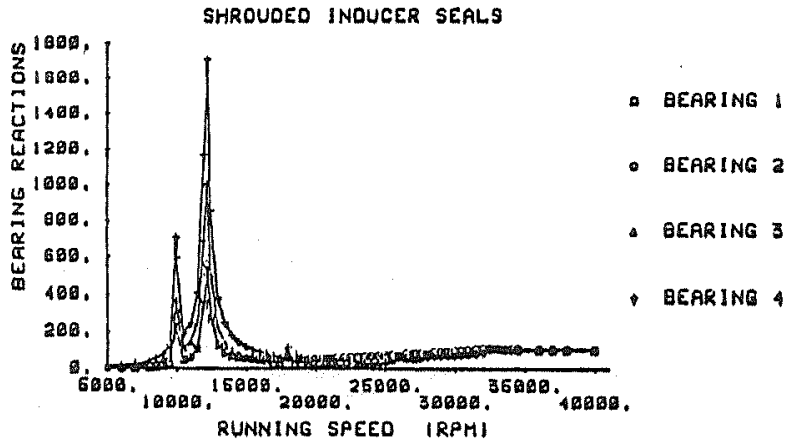

Figure 7. Bearing reactions for the model with seal coeficients for a shrouded impeller. 


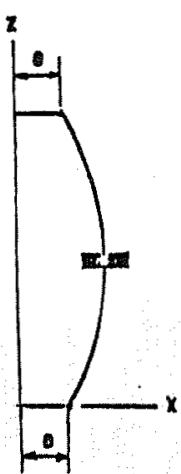

A

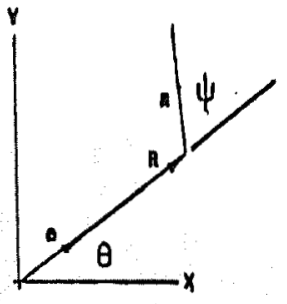

B

Figure 8, Yamamoto's model for synchronous responge with bearing clearance.

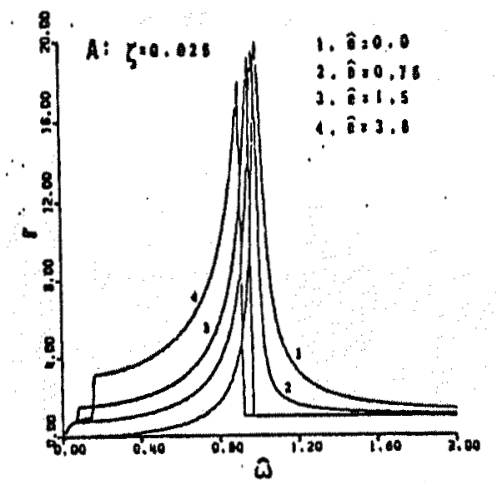

Figure 9. Synchronous-response characterlstics for Yamamoto's model with increasing bearing clearances. 


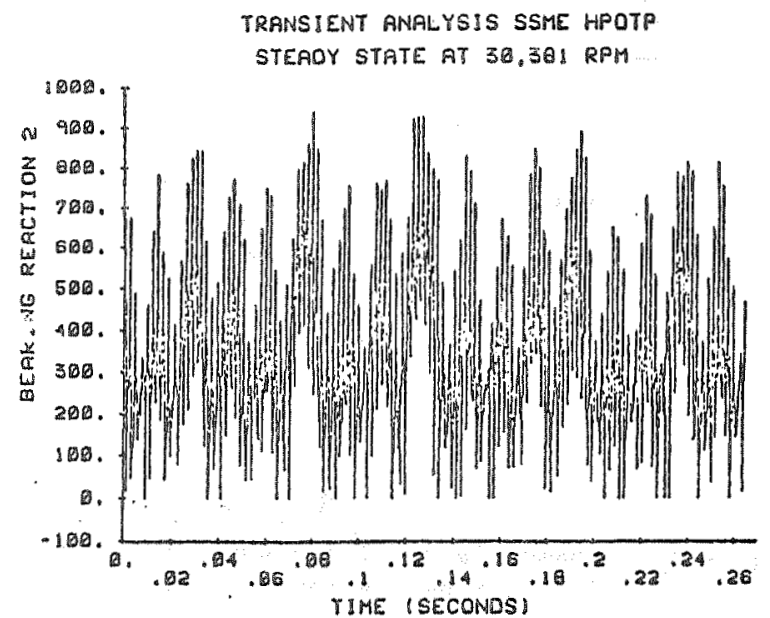

Pgure 10 (a). Bearing 2 reaction magnitude veraug time at $\mathbb{P L L}$ for the nominal nonilnear model.

TRANSIENT ANRLYSIS SSME HPOTP STEADY STATE AT 30,361 RPM

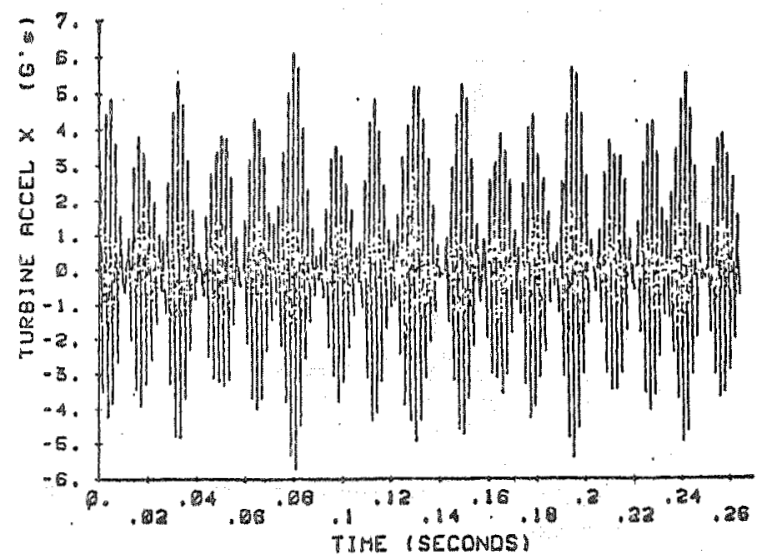

Figure 10 (b). Turbine $X_{-Z} Z$ plane acceleration magnitude veraug time for the nominal nonlinear model. 


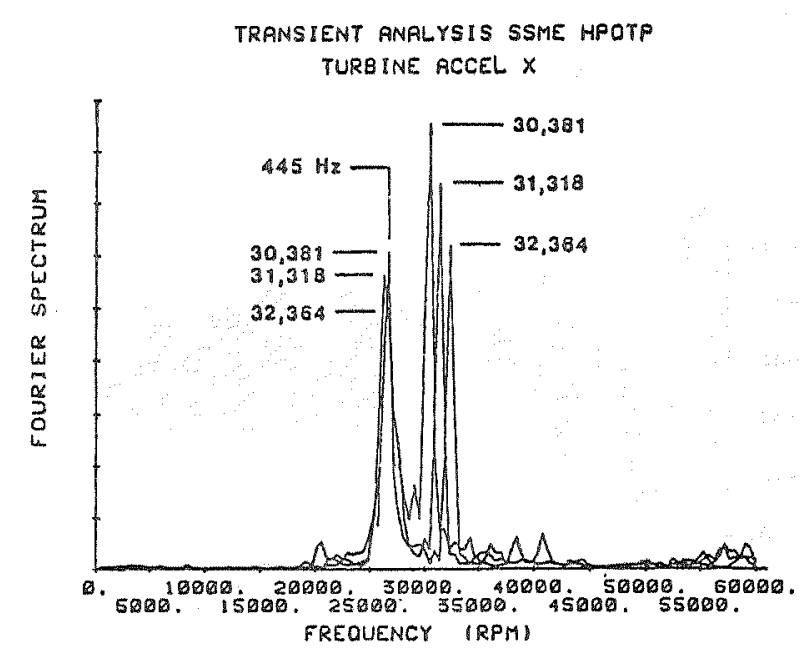

Flgure 11. Turbine $\mathrm{X}-2$ plane acceleration spectra at FPL and higher speeds for the nominal. nonlinear model.

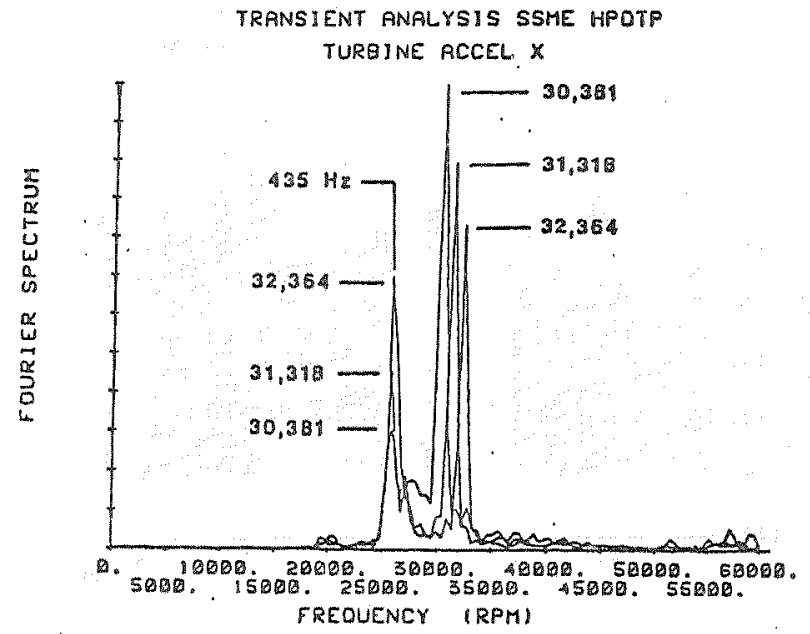

Figure 12. Turbine $X-2$ plane acceleration spectra at FPL and higher speeds for nonlinear model number 2 . 
TRANSIENT ANALYSIS SSME HPOTP

STEADY STATE AT 29,500 W/ OAMPER SEALS

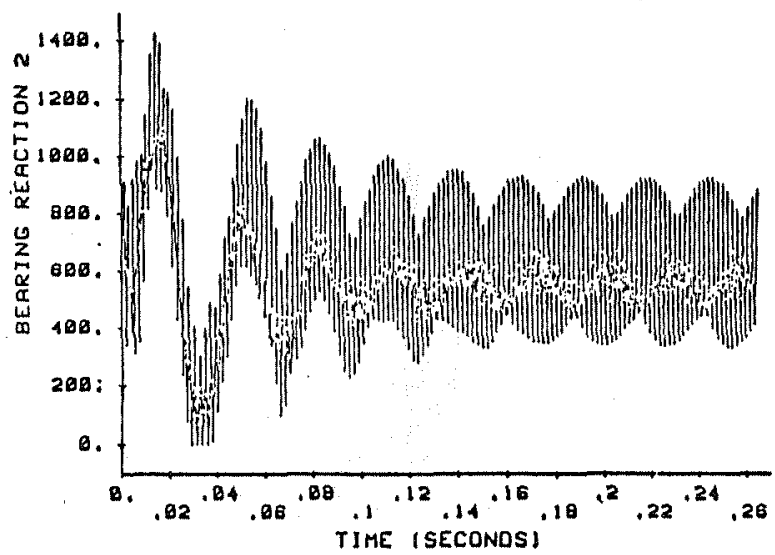

Figure 13. Bearing 2 reaction magnitude at 29,500 cpm for the nominal nonlinear model with damper seals at the boost Impeller. STEADY STATE AT 32,364 W/ DAMPER SEALS

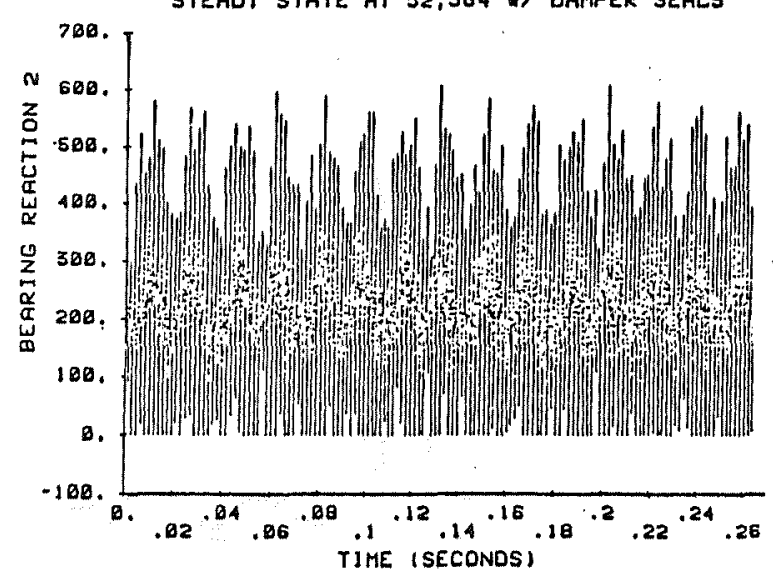

Figure 14. Bearing 2 reaction magnitude at above FPL for the nominal nonlinear model with damper seals at the boost impeller. 


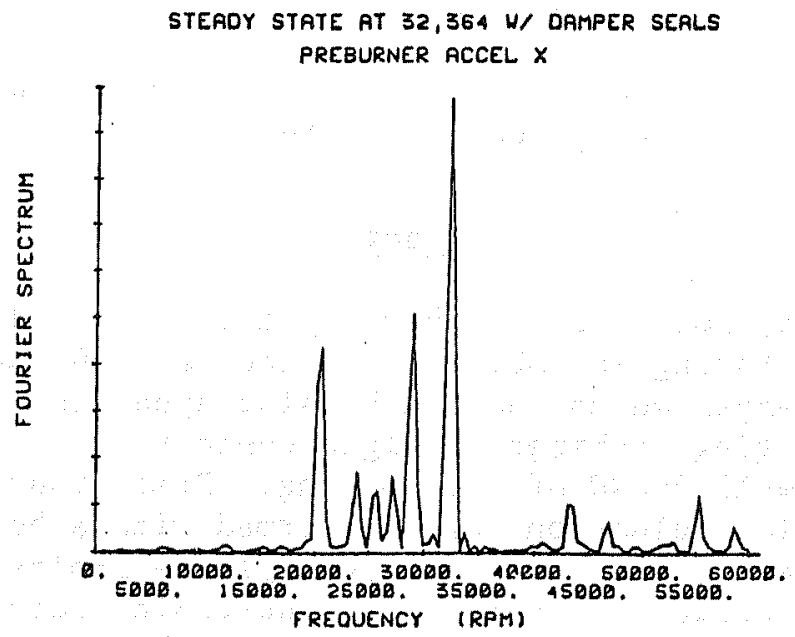

P1gure 15. Preburner $X-2$ accelerometer spectrum at FPL for the nominal nonlinear model with damper seals at the boost imeller. 